\title{
Sharing personal information: how to decide whether to or not
}

\section{Sam Rowlands}

\section{Introduction}

Without assurances about confidentiality, clients (confiders) may be reluctant to give health professionals (confidants) the information they need in order to provide good care. In a European Court of Human Rights case, a woman's doctor had been compelled to reveal her HIV positivity in court in connection with the investigation of sexual offences committed by her husband. Also her complete medical records had been seized. In this case the judges said that: "Respecting the confidentiality of health data is a vital principle in the legal systems of all [countries]. It is crucial not only to respect the sense of privacy of a patient but also to preserve his or her confidence in the medical profession and in the health services in general. Without such protection, those in need of medical assistance may be deterred from revealing such information of a personal and intimate nature as may be necessary in order to receive appropriate treatment, and, even, from seeking such assistance, thereby endangering their own health and, in the case of transmissible diseases, that of the community". ${ }^{1}$ Clients should be made aware that there are exceptions to keeping confidences and a general idea of what these are.

Confidentiality is overwhelmingly an ethical principle, with health professionals bound by professional codes. 2,3 But, legally, there is a public interest in the protection of confidential information received in circumstances that import a duty of confidentiality. ${ }^{4}$ There is substantial statute law (made by Parliament) and case law (made by judges in courts) on confidentiality that clinicians need to be aware of.

Two European influences have had significant impact on current practice. The first is EC Directive 95/46/EC which brought about the Data Protection Act 1998. The Data Protection Act 1998 goes much wider than the Data Protection Act 1984. Data protection is comprehensively covered by Faculty guidance 5 and this article will concentrate mainly on other aspects of confidentiality.

The second European influence has been the European Convention on Human Rights. ${ }^{6}$ Article 8 of the Convention states that "everyone has the right to respect for his private and family life, his home and his correspondence". Article 8 essentially boils down to the right of privacy, and this right to privacy strengthens the legal basis of confidentiality. The Human Rights Act 1998 renders the Convention Articles enforceable against public authorities, which includes the National Health Service. A European human rights case concerning the sexual orientation of a Northern Irish man suggested that the more intimate the issue in question, the stronger the protection of privacy that is needed.?

J Fam Plann Reprod Health Care 2010; 36(3): 161-165 (Accepted 4 May 2010)

Institute of Clinical Education, Warwick Medical School, University of Warwick, Warwick, UK

Sam Rowlands, LLM, MD, Honorary Associate Professor

Correspondence to: Dr Sam Rowlands, Institute of Clinical Education, Warwick Medical School, Gibbet Hill Campus, University of Warwick, Coventry CV4 7AL, UK.

E-mail:sam.rowlands@warwick.ac.uk

\section{Key message points}

- Information sharing among health care and allied professions is becoming increasingly necessary.

- Disclosure of certain information is statutory and there is a legal and professional duty to breach confidentiality.

- Sharing of information without consent may be needed in cases of child abuse or domestic violence.

- The sexual partner of an HIV-positive individual may in certain circumstances need to be told about their risk without their partner's consent if this information is being withheld.

- Use of medical records for research purposes without consent by those outside the health care team will not continue in the longer term.

Article 8 is, however, not an absolute right: there are exceptions in case of national security, public safety, the prevention of disorder or crime, the protection of health or morals, and for the protection of the rights and freedoms of others. The European Court of Human Rights has upheld seizure of medical records in criminal proceedings ${ }^{1}$ and in connection with social security benefits. ${ }^{8}$

\section{Inadvertent breaches of confidentiality}

Confidentiality is not just a negative concept: the obligation of health care staff not to reveal personal information. It also contains a positive obligation: taking steps to ensure that information is protected. ${ }^{2,9}$

Clearly it is vital that conversations between colleagues about a client's care should not be overheard. Nor should records or appointment lists be left where they may be seen by unauthorised people.

With computerisation of records, safeguards need to be in place including password protection. Screens need to be well away from prying eyes. Data should be encrypted if it is going to be transferred electronically. ${ }^{10}$ One Primary Care Trust (PCT) admitted losing the data of 160000 children. ${ }^{11}$ It appears loss of data is widespread. ${ }^{12}$ Between January and April 2009, 140 security breaches were reported within the National Health Service (NHS).13 Between November 2008 and April 2009, the Information Commissioner had to take enforcement action against 14 NHS organisations for data breaches. ${ }^{14}$ As a result of these breaches of the Data Protection Act 1998, the chief executives of the Trusts concerned have had to sign formal undertakings regarding data security. The Ministry of Justice has announced plans to increase the powers of the Information Commissioner's Office. ${ }^{15} \mathrm{~A}$ substantial number of breaches involve theft from cars. There need to be tighter protocols for the use of laptops, compact disks and memory sticks.

\section{Deliberate breaching of confidentiality}

The main difficulties in medical practice arise when trying to work out in what circumstances it is right to breach confidentiality. Increasingly, the term 'sharing information' is being used. This will be the main focus of the remainder of this article. Topics will be confined to those of particular interest and relevance to practitioners in sexual and reproductive health care. 
For health professionals, breaching confidentiality instinctively goes against the grain. Considerable thought needs to go into whether or not information should be shared, particularly if this is without the client's knowledge. Discussion with a senior colleague with documentation in the notes is good practice, and is essential for less experienced clinicians.

\section{With consent}

The first, rather obvious, instance when information can be shared is when the client agrees to it. Clients can choose to waive the obligation of confidentiality and allow clinicians to disclose confidential information to others, for example to relatives. ${ }^{2}$ Interestingly, under the Human Fertilisation and Embryology Act 1990, clients were unable to authorise relevant medical personnel including their general practitioners (GPs) to be told about their infertility treatment. The Human Fertilisation and Embryology (Disclosure of Information) Act 1992 was enacted to allow this.

A psychiatrist expert witness was found liable in the Court of Appeal for breaching confidentiality when she sent information to a claimant's GP and to another psychiatrist without consent. 16

\section{The need to know}

The second general exception to the obligation of keeping information confidential is the need to know; colleagues in health care teams need access to personal information for the effective delivery of health care; ${ }^{2}$ this includes administrative staff. ${ }^{17}$ Trainees who are part of the health care team providing or supporting care will need to know; undergraduate students not providing or supporting care should in general see anonymised information only. ${ }^{17}$ How much this consent is implied when, for instance, a patient enters a surgery, clinic or hospital is tricky. Does the patient understand about the complaints system, risk management and general management of services, all of which require non-medical staff to deal with personal information? ${ }^{18}$

The wishes of any client who objects to particular information being shared with others providing care must be respected, except where this would put others at risk of death or serious harm. ${ }^{2,19}$ A common example of this is women who have abortions declining permission for a discharge letter to be sent to their GP. Another example is the HIV-positive client who declines permission for their GP to be notified of the diagnosis and who has no sexual partner or whose sexual partner is not being put at risk of transmission (see section on HIV status). Local clinical audit and case review is essential to the provision of good care. ${ }^{2}$ Where this audit is within the team providing the care, identifiable information may be used if clients have been made aware that this activity goes on and have not objected. In general, however, it is better practice to use anonymised data. ${ }^{17}$

\section{The public interest}

Remaining instances where disclosure of confidential information may be justifiable are when it is in the public interest to do so. Legally, there are three principles that need to be fulfilled: 20

- A real and serious risk of danger to the public must be shown.

- Disclosure must be to a person with a legitimate interest in receiving the information.

- The information disclosed should be confined to that which is strictly necessary.
Situations in which confidentiality must be breached

There are several clear-cut situations in which health professionals have a legal and/or professional duty to breach confidentiality. These are either when disclosure is required by law or is justified in the public interest. ${ }^{2}$

\section{Compulsory disclosure}

Compulsory disclosure is permitted under Schedule 2 of the Data Protection Act 1998. For instance, doctors have a duty under Section 2 of the Abortion Act 1967 and related secondary legislation ${ }^{21,22}$ to notify abortions to the Chief Medical Officer on the HSA4 form, which contains identifiers including date of birth and postcode.

\section{Regulatory bodies}

The NHS Counter Fraud and Security Management Service has powers to require the production of documents to prevent, detect and prosecute fraud in the NHS. ${ }^{23}$ The General Medical Council (GMC) has powers to require disclosure of information necessary for the discharge of fitness to practise functions. ${ }^{24,25}$

\section{Public health}

It is considered necessary to disclose information relevant to safeguarding the public health. ${ }^{17}$ Legitimate bodies that safeguard public health include the Medicines and Healthcare Products Regulatory Agency, Commission on Human Medicines, Drug Safety Research Unit, Health Protection Agency, ${ }^{26}$ Centre for Maternal and Child Enquiries and the Care Quality Commission. ${ }^{27}$

\section{Situations in which confidentiality may be breached}

In this section, three often difficult aspects of clinical practice will be used as illustrations. The need to interview the client on their own to facilitate disclosure of information by them cannot be overemphasised.

\section{Safeguarding young people}

It should be noted that Section 11 of the Children Act 2004 sets out an obligation on the health service to safeguard and promote the welfare of children and to have due regard for guidance issued by the Secretary of State. Services provided on behalf of primary care organisations must fulfil this obligation. Where a clinician has a reasonable cause to believe that a young person may be suffering or may be at risk of suffering significant harm, voicing concerns to children's social care or the police, in line with Local Safeguarding Children Board procedures, should be considered. ${ }^{28,29}$

If abuse of any kind comes to light in a consultation with a young person, there is no doubt that breaching confidence is lawful. ${ }^{30}$ When a parent is alleged to be the perpetrator, parental rights must be forfeited on the grounds of improper behaviour; 31 doctors are covered here by GMC guidance. ${ }^{2}$ This sharing of information would generally be done after informing the young person of the need to do so. Automatic disclosure in cases of sexually active under-13s remains a controversial area of clinical practice. ${ }^{32}$ Current guidance from the Department for Education is that cases involving under-13s should always be discussed with a nominated child protection lead in the organisation. 33 Child protection staff have access to at-risk registers, and if given the name of a partner can check their own records or records of colleagues in other regions of the country in order to ascertain if that person is known to the police. The guidance goes on to say that there is a presumption that the case will be reported to children's social care and that there 
should be full documentation, including detailed reasons where a decision is taken not to share information.

The reason that there is so much emphasis on under-16s is because of the wording of the Sexual Offences Act 2003. Engaging in any sexual activity by a person of any age with another person who is under 16 is a criminal offence, regardless of consent. Under-13s are categorised separately in Sections 5 to 8 of the Act: penile penetration is classified as rape and other forms of sexual contact are classed as serious criminal offences. It is well known that prosecutions are rare, but this does not detract from the need to be cognisant of the criminal law in relation to young people. The likelihood of police prosecution is much greater when there is a large age difference between an under-13 and their partner.

Cases in which breaching confidentiality needs to be seriously considered include those where there is reported coercion to take part in sexual activity, where the sexual partner is much older or where there is a suspicion of grooming or payment. The Sexual Offences Act 2003 created a number of specific offences relating to the abuse of young people exploited through prostitution; clinicians need an awareness of commercial sexual exploitation of young people. ${ }^{33}$

\section{Domestic violence}

Domestic violence claims the lives of two women every week in England and Wales. ${ }^{34}$ Failure to share information with other agencies may cost women's lives. ${ }^{34,35}$ Under Section 115 of the Crime and Disorder Act 1998, information should be passed to another agency when there is significant risk of harm to a woman, her children or someone else if the information is not passed on. It is particularly recognised that where there are reasons to believe that children are at significant risk of harm as a result of domestic violence, safeguarding must take precedence over confidentiality. 36 Health care professionals may need on occasions to decide to set aside a consent-based approach because if consent is sought but refused it is not good practice to then share on a different basis. Many health care professionals now work in settings in which a protocol for sharing information for risk assessment purposes has been drawn up by a multi-agency partnership.

There will be a spectrum of cases experienced and the more severe cases will be easier to decide upon. It is not uncommon to see women who are clearly in abusive relationships, but there appears to be some sort of equilibrium, with the woman declining escape from the relationship. In these sorts of cases, clinicians need to assess the risk of harm and if it is thought low to continue to monitor the situation and offer support to the woman, rather than breaching confidentiality.

\section{HIV status}

The general principle of partner notification is that the identity of the index case must not be disclosed.17 However, the NHS Trusts and Primary Care Trusts (Sexually Transmitted Diseases) Directions 2000 (England) specify an exception to keeping information confidential: for the purposes of the prevention of the spread of sexually transmitted infections (STIs). GMC guidance $^{2}$ states that "personal information may be disclosed in the public interest, without patients' consent, and in exceptional cases where patients have withheld consent, if the benefits to an individual or to society of the disclosure outweigh both the public and the patient's interest in keeping the information confidential". In such circumstances, the client should preferably be told before making the disclosure and justification of the disclosure may be required.

There have been 18 criminal prosecutions and 14 convictions for the reckless transmission of HIV in the UK ${ }^{37,38}$ English cases have been brought under Section 20 of the Offences Against the Person Act 1861 for recklessly inflicting grievous bodily harm; in Scots law the prosecution is under the common law crime of culpable and reckless conduct. ${ }^{39}$ All cases involved heterosexual transmission of HIV, and most resulted in substantial custodial sentences for the accused. It is clear that people living with HIV need to be aware of the risk of legal action if they do not disclose their status to sexual partners and there is onward transmission of HIV. However, prosecutions are now less likely to occur in England and Wales as a result of Crown Prosecution Service guidance issued in March 2008.40 In Scotland, a recent prosecution was successful, even where on one of the four charges HIV transmission was shown not to have occurred. ${ }^{38}$

Health professionals diagnosing HIV have a duty to explain about ways of protecting others from infection. If a clinician knows an identified individual to be at risk of HIV infection and the index patient cannot be persuaded to inform their sexual partner, it has been argued that the clinician has a duty of care to advise that partner that they may be at risk. 41 Where possible, this should be accomplished without revealing the identity of the index patient. If a patient with HIV (whether diagnosed or not some people are at high risk but decline a test) is not properly advised and HIV is transmitted to a sexual partner, the professional is potentially liable for damages. Such liability in negligence has not been reported in the UK, but it has been in Australia, Canada and the USA and it is thought that courts in the UK would make similar determinations. ${ }^{42}$ Case law outside the UK suggests that such liability would be more likely to be found if both partners are patients of the doctor concerned; ${ }^{43}$ such a duty to prevent onward transmission would be less likely owed to a third party with whom the doctor has no direct contact.

As usual, there is a range of cases seen in clinical practice. The case of a discordant couple where the positive individual is reported to be using barrier contraception consistently will be less likely to require a breach of confidentiality than a couple where the seropositive individual is reported not to be using a barrier.

\section{Research}

Pharmacists who sold fully anonymised (unlinked) data to industry have been held in the Court of Appeal not to be in breach of confidence. ${ }^{44}$ Section 251 of the National Health Service Act 2006 empowers the Secretary of State to support the use of confidential medical information to improve individual health care or in the public interest without the person's consent, provided there is no practicable alternative. The Health and Social Care Act 2008 establishes the National Information Governance Board for Health and Social Care (NIGB) (http://www.nigb.nhs.uk/) as the statutory body empowered to consider applications for approval for research where it is considered that the research is so important that the common law duty of confidentiality should be set aside (this body replaces the Patient Information Advisory Group). The NIGB has agreed to delegate its responsibility for administering Section 251 powers to its Ethics and Confidentiality Committee. Examples of critically important research using this kind of release without consent are the two UK oral contraception cohort studies, 45,46 the Million Women Study 47 and the RIPPLE study. ${ }^{48}$ In such studies, the records of individuals 
are flagged so that they can be followed as they change general practice or die. But this sidestepping of normal confidentiality protocol is not likely to continue in the longer term. In future researchers will be expected to gain consent from their study participants when secondary analysis of data is performed or will need to anonymise the data from the outset. ${ }^{49}$ Those subjects who refuse to consent will not then be included.

In retrospective analyses, in which consent is not obtained from the subjects, access to medical records must now be restricted to the health care team. 50 Other researchers may then conduct analysis on data that is free from identifiers.

\section{Press freedom}

Article 10 of the European Convention guarantees freedom of expression; it competes with Article 8. Free speech is restricted by the courts only where the requirements for confidentiality are particularly strong, such as a court's decision in cases of child welfare. ${ }^{51}$ In the 1980 s there was considerable public debate about HIV, much more than now when HIV is a treatable condition. Staff at a hospital that treated two HIV-positive GPs leaked their identities to a newspaper reporter, not only breaching their ethical codes, but in direct contravention of the National Health Service (Venereal Diseases) Regulations 1974. A permanent injunction was granted to the health authority and the newspaper was fined $£ 10000.52$

In a more recent case, Naomi Campbell was photographed outside a building in which meetings of Narcotics Anonymous took place. The photograph was published in the Daily Mirror. Naomi Campbell's attendance at Narcotics Anonymous was held in the House of Lords to be of a private nature and entitled to protection from publication. ${ }^{53}$ Baroness Hale felt that information relating to Naomi Campbell's physical and mental health was private and confidential. Lord Hope said that disclosure of this information would be liable to disrupt her treatment and that a person with a drug addiction would find this disclosure distressing and highly offensive.

\section{Young people: a challenge to the status quo}

Sue Axon applied for judicial review of Department of Health guidance on treating young people under the age of 16 in relation to sexual and reproductive matters. ${ }^{54} \mathrm{Ms}$ Axon was concerned about parental Article 8 rights: the right to give consent on behalf of their child. She felt that disclosure of confidential information about their child would enable parents to fulfil their responsibilities for ensuring the health and well-being of the child. Axon failed in her claim: the judgment was that where parental Article 8 rights conflict with those of their children, the latter should prevail. ${ }^{55}$ Judge Silber drew attention to the United Nations Convention on the Rights of the Child ${ }^{56}$ and said that there had been a change in the landscape of family matters. The autonomy, self-determination and rights of young people were of the utmost importance. Therefore health professionals owe young people a duty of confidentiality. Clearly the Fraser guidelines should be followed. 57 But the law recognises that an obligation of confidentiality is owed to both Gillick-competent and noncompetent children. $55,58,59$ In this regard, the law differs from that relating to consent. Nevertheless, the bottom line is that health professionals have a legal and professional duty to act in a young person's best interests and this will always trump the right of young people to have their autonomy and confidentiality respected. ${ }^{18,60}$

\section{Discussion}

Sharing information with other agencies without a person's knowledge at first sight seems an anathema. This article has demonstrated that in some cases, such as domestic violence, this may be the right thing to do, ethically and legally, and may even save a life.

Modern health care is more complex than traditional one-to-one consultations where the Hippocratic Oath or similar ethical codes could be applied. There are teams within health care settings and wider multi-agency teams that information needs to be shared with in order to provide high-quality care and to protect vulnerable individuals.

It is impossible to deliver modern health care without teamwork. Computerisation of information brings its own problems of vulnerability through breaches in security. In general, individuals have the right to privacy and the right to know if their personal information is being divulged. Nevertheless, the instances where sharing of information under the heading of the public interest have increased. Compulsory disclosure is arguably unnecessary, unless of course this is at the direction of a judge in a court of law. There is no reason for information on abortions to contain identifiers - information can be collected just like for other procedures.

Countering fraud and investigating underperforming doctors would seem to be laudable activities, but possible adverse effects of these instances of information sharing on the public's trust in their health care provision needs to be considered. Few would argue against safeguarding the public health, but do all members of the public realise that non-medical inspectors have access to their records?

Balancing the preservation of confidentiality in cases of sexually active young people and in domestic violence is one of the hardest challenges that health professionals can face. The knowledge that cases can be discussed with other agencies initially without identifying the individual is reassuring. What may not be fully realised is how widespread sexual offences and violence are 61 and how perpetrators often have previous convictions or are otherwise known to the police.

There has been considerable discussion about transmission of HIV being classed as a criminal act. ${ }^{40}$ Even if it were not so, there may be occasions when it would appear to be ethically justifiable to inform a sexual partner of their risk.

Care is needed to obtain consent when conducting research. The Integrated Research Application System (IRAS) is explicit about this and alerts researchers to keeping information within the health care team if there is no such consent. The NIGB is determined to phase out studies in which identifiable information is used by researchers without explicit consent. Academics have been concerned about this 62 but the right to privacy is enjoying a higher profile nowadays. And although freedom of the press is also a human right, this will be curtailed if it can be demonstrated that release of medical information would be harmful to an individual's medical treatment and their confidence in their health care providers.

There is an increasing recognition of the rights of young people to confidentiality. The Axon case ${ }^{55}$ was important in clarifying these rights, giving confidence to both young people and those treating them that their autonomy must be respected.

Who is out there to give specialist advice to clinicians on confidentiality? Caldicott Guardians ${ }^{63}$ are there to oversee procedures but also to act as a valuable resource when staff are working out whether or not to share information. Defence organisations may also be consulted. 
Statements on funding and competing interests

Funding None identified.

Competing interests None identified.

Editor's note

This is the first article in a new series of occasional articles that will explore legal themes of relevance to sexual and reproductive health.

\section{Author's note}

Interested readers who wish to view or download any statute mentioned in this article should refer to the UK Statute Law Database website (http://www.statutelaw.gov.uk).

\section{References}

$1 \quad$ Z v Finland (1997) 25 EHRR 371.

2 General Medical Council. Confidentiality. 2009. http://www. gmc-uk.org/guidance/ethical_guidance/confidentiality.asp [Accessed 25 April 2010].

3 The Code: Standards of Conduct, Performance and Ethics for Nurses and Midwives. London, UK: Nursing and Midwifery Council, 2008.

4 Attorney General v Guardian Newspapers (No. 2) [1988] 3 All ER 545 .

5 Faculty of Sexual and Reproductive Healthcare. Service Standards on Confidentiality. 2009. http://www.fsrh.org/admin/ uploads/ServiceStandardsOnConfidentiality.pdf [Accessed 25 April 2010].

6 European Convention on the Protection of Human Rights and Fundamental Freedoms. 1950. http://conventions.coe.int/ treaty/EN/Treaties/html/005.htm [Accessed 25 April 2010].

7 Dudgeon v UK (1981) 4 EHRR 149.

8 MS $v$ Sweden [1997] 45 BMLR 133

9 Herring J. Medical Law and Ethics (2nd edn). Oxford, UK: Oxford University Press, 2008.

10 British Medical Association. 2009. Confidentiality and Disclosure of Health Information Tool Kit. http://www.bma. org.uk/ethics/confidentiality/confidentialitytoolkit.jsp [Accessed 25 April 2010].

11 Rose D. More personal data lost as nine NHS Trusts admit security breaches. The Times, 24 December 2007

12 Russell B. Catalogue of NHS data losses makes shocking reading. Independent, 26 November 2008.

13 Savage M. NHS 'loses' thousands of medical records. Independent, 25 May 2009.

14 Information Commissioner's Office. ICO issues stark reminder to NHS bodies on patient records. 2009. http://www.ico.gov.uk [Accessed 25 April 2009].

15 Ministry of Justice. Information Commissioner to be given tougher powers. 2008. http://www.justice.gov.uk/news/news release241108a.htm [Accessed 25 April 2010].

16 de Taranto $v$ Cornelius [2001] EWCA Civ 1511

17 General Medical Council. Confidentiality: Supplementary Guidance. 2009. http://www.gmc-uk.org/guidance/ethical_ guidance/confidentiality.asp [Accessed 25 April 2010].

18 Montgomery J. Health Care Law. Oxford, UK: Oxford University Press, 2003.

19 Department of Health. Confidentiality: NHS Code of Practice. 2003. http://www.dh.gov.uk/prod consum dh/groups/dh digitalassets/@dh/@en/documents/digitalasset/dh_4069254. pdf [Accessed 25 April 2010].

20 W v Egdell [1990] 1 All ER 835.

21 Abortion Regulations 1991. (SI 1991 No. 499).

22 Abortion (Scotland) Regulations, 1991. SI 1991/460.

23 National Health Service Act 2006.

24 Medical Act1983.

$25 \operatorname{Re} A$ (A Minor) (Disclosure of Medical Records to GMC) [1999] 1 FCR 30.

26 Health Service (Control of Patient Information) Regulations 2002. (No. 1438).

27 Health and Social Care Act 2008.

28 Department for Children, Schools and Families. 2008. Information Sharing: Guidance for Practitioners and Managers. http://www.dcsf.gov.uk/everychildmatters [Accessed 25 April 2010].

29 Department for Children, Schools and Families. 2009. Information Sharing: Further Guidance on Legal Issues. http://www.dcsf.gov.uk/everychildmatters [Accessed 25 April 2010].

$30 \operatorname{Re} M$ and another (minors) (wardship: freedom of publication) [1990] 1 All ER 205.

31 D v NSPCC [1977] 1 All ER 589.

32 Bastable R, Sheather J. Mandatory reporting to the police of all sexually active under-13s. BMJ 2005; 331: 918-919.

33 Department for Education. 2010. Working Together to Safeguard Children: A Guide to Inter-agency Working to Safeguard and Promote the Welfare of Children. 2010. http://publications.dcsf.gov.uk/eOrderingDownload/ 003052010DOM-EN.PDF [Accessed 25 April 2010].

34 Douglas N, Lilley S, Kooper L, Diamond A. Safety and Justice: Sharing Personal Information in the Context of Domestic Violence - An Overview. London, UK: Home Office, 2004.

35 Department of Health. Responding to Domestic Abuse: A Handbook for Health Professionals. 2005. http://www.domestic violencelondon.nhs.uk/uploads/downloads/DH_4126619.pdf [Accessed 25 April 2010].

36 British Medical Association (BMA) Board of Science. Domestic Abuse. London, UK: BMA, 2007.

37 NAMLIFE. HIV Transmission and the Criminal Law. http://www.namlife.org [Accessed 25 April 2010].

38 Ten-year sentence in Scottish HIV prosecution. http://www. aidsmap.com/en/news/126BD9F1-8F44-44A8-8AAB-C4DDBF 736909.asp [Accessed 25 April 2010].

39 Chalmers J. Legal Responses to HIV and AIDS. Oxford, UK: Hart Publishing, 2008.

40 Azad Y. Developing guidance for HIV prosecutions: an example of harm reduction? HIV AIDS Policy Law Rev 2008; 13: 13-19.

41 Expert Advisory Group on AIDS. Policy on confidentiality and disclosure of patient information: HIV and sexually transmitted infections. Response to a consultation. 2006. http://www.dh. gov.uk/ab/EAGA/DH_094975 [Accessed 25 April 2010]

42 Chalmers J. Criminalisation of HIV transmission: can doctors be liable for the onward transmission of HIV? Int J STD AIDS 2004; 15: 782-787.

43 Harvey $v$ PD [2004] NSWCA 97.

$44 R v$ Department of Health, ex parte Source Informatics Ltd [2000] 1 All ER 786.

45 Hannaford PC, Iversen L, Macfarlane TV, Elliott AM, Angus V, Lee AJ. Mortality among contraceptive pill users: cohort evidence from Royal College of General Practitioners' Oral Contraception Study. BMJ 2010; 340: c927.

46 Vessey M, Painter R. Oral contraceptive use and cancer. Findings in a large cohort study, 1968-2004. Br J Cancer 2006; 95: 385-389.

47 Beral V. Ovarian cancer and hormone replacement therapy in the Million Women Study. Lancet 2007; 369: 1703-1710.

48 Stephenson JM, Strange V, Forrest S, Oakley A, Copas A, Allen $\mathrm{E}$, et al. Pupil-led sex education in England (RIPPLE study): cluster randomised intervention trial. Lancet 2004; 364: 338-346.

49 Higgins J. Two sides of the fence. Health Serv J 2004; 20-21.

50 Integrated Research Application System (IRAS). 2009. https://myresearchproject.org.uk [Accessed 25 April 2010].

$51 R v$ Central Independent Television [1994] 3 All ER 641.

$52 X v Y$ [1988] 2 All ER 648.

53 Campbell v Mirror Group Newspapers Ltd [2004] 2 All ER 995.

54 Department of Health. Best Practice Guidance for Doctors and Other Health Professionals on the Provision of Advice and Treatment to Young People Under 16 on Contraception, Sexual and Reproductive Health. 2004. http://www.dh.gov.uk/en/ Publicationsandstatistics/Publications/PublicationsPolicyAndG uidance/DH 4086960 [Accessed 25 April 2010].

$55 R$ (on the application of Axon) $v$ Secretary of State for Health \& Family Planning Association [2006] EWHC 372 (Admin).

56 United Nations. Convention on the Rights of the Child. 1989. http://www2.ohcr.org/english/law/crc.htm [Accessed 25 April 2010].

57 Gillick $v$ West Norfolk and Wisbech Area Health Authority [1985] 3 All ER 402.

58 Re C (a minor) (wardship: medical treatment) (No 2) [1989] 2 All ER 791.

59 Venables v News Group Newspapers Ltd, Thompson v News Group Newspapers Ltd [2001] 1 All ER 908.

60 General Medical Council. 2007. 0-18 Years: Guidance for Doctors. http://www.gmc-uk.org/guidance/ethical guidance/ children_guidance_index.asp [Accessed 25 April 2010]

61 Home Office. 2009. Crime in England and Wales 2008/9. http://rds.homeoffice.gov.uk/rds/crimeew0809.html [Accessed 25 April 2010].

62 Walley T. Using personal health information in medical research. BMJ 2006; 332: 130-131.

63 Department of Health. The Caldicott Guardian Manual 2010 2010. http://www.dh.gov.uk/prod_consum_dh/groups/dh_digi tal/assets/@dh/@en/@ps/documents/digitalasset/dh_114506 [Accessed 25 April 2010]. 